\title{
SEPARATION OF GASES USING ULTRA-THIN POROUS LAYERS OF MONODISPERSE NANOPARTICLES
}

\author{
Mikhail A Bubenchikov ${ }^{1}$, Alexey M Bubenchikov ${ }^{1}$, Olesya $\vee$ Usenko ${ }^{1,}$, , Valentina A Poteryaeva ${ }^{1}$ and \\ Soninbayar Jambaa ${ }^{1}$ \\ ${ }^{1}$ National Research Tomsk State University, 634050, 36 Lenin av., Tomsk, Russia
}

\begin{abstract}
The present paper deals with a numerical solution of the two-dimensional problem of helium and methane molecules motion through an ultra-thin layer of a porous material composed of spherical nanoparticles of the same size. The interaction potential "nanoparticlemolecule" is obtained by integrating paired molecular interactions over the nanoparticle volume. Using the method of classical molecular dynamics, permeability of a layer having the size of about $10^{-8} \mathrm{~m}$ is studied.
\end{abstract}

\section{Introduction}

Production and study of membranes' physical properties is relevant for the process of separating small molecules from macromolecules [1, 2] in evaluation of catalysts [3, 4]. On the basis of nanoporous membranes it is possible to design filters for biomolecules separation $[5,6]$, as well as water filters [79]. There is a growing need for increasing efficiency and selectivity of mixtures separation [10]. In this respect, the role of nanoporous membranes is becoming more noticeable [11]. New technologies of creating such membranes are being developed. For example, track-etched membranes [12] can be produced on the basis of organic molecules [13], proteins [14], copolymers $[9,15,16]$, anodic alumina $[1,17,18]$, silicon oxide and dioxide [6, 19], silicon [20] and silicon nitride [21].

Compacted filter layers made of common materials are of particular interest. The example can be carbon materials.

In this paper, when determining layer permeability, we use the following approach. A rectangular box with transparent bases and sides reflecting molecules according to laws of geometrical optics is randomly filled with nanoparticles achieving the required density. At the same time, whenever intersections of spheres occur, we eliminate them individually by means of spacing the centres of intersecting spheres.

\section{Numerical model}

Let us write the basic equation of a moving molecule dynamics in a standard format in the form of Newton's second law:

\section{${ }^{a}$ Corresponding author: usenko.olesya@yandex.ru}




$$
M \frac{d \vec{v}}{d t}=\vec{F}
$$

where $\vec{v}$ is the molecule velocity vector, $M$ is the flying molecule mass, $\vec{F}$ is the main vector of external effects on the molecule.

In the coordinate axis projections instead of (1) we obtain three scalar equations:

$$
M \frac{d U}{d t}=X^{\prime}, M \frac{d V}{d t}=Y^{\prime}, M \frac{d W}{d t}=Z^{\prime}
$$

Here $X^{\prime}, Y^{\prime}, Z^{\prime}$ are the projections of the Van der Waals forces resultant from the carbon structure elements which are defined as simple sums of force contributions from individual particles of the system

$$
X^{\prime}=\sum_{j=1}^{N_{p}} X_{j^{\prime}}, Y^{\prime}=\sum_{j=1}^{N_{p}} Y_{j^{\prime}}, Z^{\prime}=\sum_{j=1}^{N_{p}} Z_{j^{\prime}}
$$

where $X_{j}^{\prime}, Y_{j}^{\prime}, Z_{j}^{\prime}$ are the Cartesian coordinates projections of the Van der Waals forces acting from the $j$-th particle of the system and $N_{p}$ is the number of particles.

Next, we introduce the values $X_{j}, Y_{j}, Z_{j}: X_{j^{\prime}}=M X_{j}, Y_{j^{\prime}}=M Y_{j}, Z_{j^{\prime}}=M Z_{j}$ in consideration. Then, in the new variables, equations (2) can be rewritten as:

$$
\frac{d U}{d t}=\sum_{j=1}^{N_{p}} X_{j}, \frac{d V}{d t}=\sum_{j=1}^{N_{p}} Y_{j}, \frac{d W}{d t}=\sum_{j=1}^{N_{p}} Z_{j}
$$

Wherein

$$
X_{j}=a_{j} \frac{x-x_{j}^{0}}{\rho_{j}}, Y_{j}=a_{j} \frac{y-y_{j}^{0}}{\rho_{j}}, Z_{j}=a_{j} \frac{z-z_{j}^{0}}{\rho_{j}},
$$

where $a_{j}$ is the value of acceleration which is acquired by the test molecule under the influence of the $j$-th particle of the system and $\rho_{j}$ is the distance between the $j$-th particle of the porous structure and the test molecule.

A porous body is seen as a collection of spherical nanoparticles for which there is an interaction potential "nanoparticle - molecule" [22]:

$$
U\left(\rho_{j}\right)=2 \pi q \int_{0}^{\pi} \sin \theta d \theta \int_{0}^{R} r^{\prime 2} V_{1}\left(\sqrt{r^{\prime 2}+\rho_{j}^{2}-2 r^{\prime} \rho_{j} \cos \theta}\right) d r^{\prime} .
$$

Here $\rho_{j}$ is the distance between the $j$-th particle of the porous structure and the test molecule, $R$ is nanoparticle radius, $q$ is the density of molecular distribution per unit volume of the matter and the function $\Phi_{1}(\rho)=4 \varepsilon \frac{\sigma}{\rho} \operatorname{th}\left[\left(\frac{\sigma}{\rho}\right)^{11}-\left(\frac{\sigma}{\rho}\right)^{5}\right]$ is a modified LJ-potential. The acceleration value $a_{j}$, which is included in the right-hand sides of relations (5), will be derived from (6) with respect to $\rho_{j}$ :

$$
a_{j}=\frac{d U\left(\rho_{j}\right)}{d \rho_{j}}
$$


If the centres of spherical nanoparticles are coplanar, and the initial velocity vector of the molecule is in the same plane, the problem of interaction between the molecule and the nanoparticle system will be plain. For the reasons of saving estimated time on a standard PC, let us consider this particular situation. When implementing the Runge-Kutta technology [23], with the help of which we integrate equations (4), point interpolation over the values in the nodes of an elementary flat cell is required. It will look as follows (Figure 1):

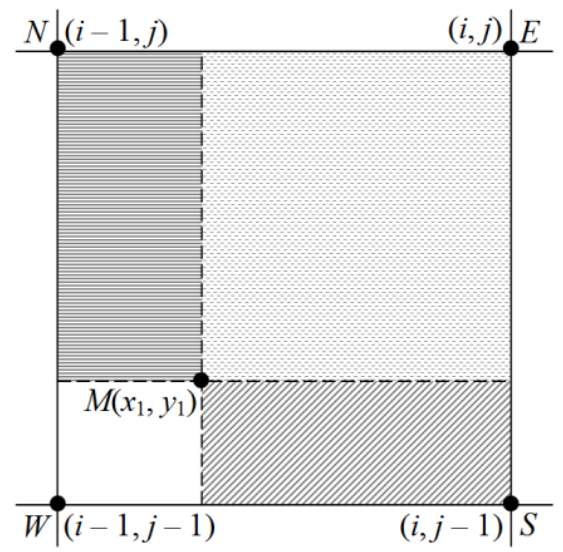

Figure 1. Linear interpolation over alternative areas.

Let us conduct interpolation to the point $M$ over the values of the unknown value $U$ at the points $W, S, E, N$. For this purpose, we initially measure densities of the areas adjacent to the nodal points:

$$
\left.\begin{array}{ll}
S_{W}=\left(x_{1}-x_{W}\right)\left(y_{1}-y_{W}\right), & S_{N}=\left(x_{1}-x_{N}\right)\left(y_{N}-y_{1}\right), \\
S_{E}=\left(x_{1}-x_{E}\right)\left(y_{1}-y_{E}\right), & S_{S}=\left(x_{1}-x_{S}\right)\left(y_{S}-y_{1}\right) .
\end{array}\right\}
$$

We also determine the area of the whole differential cell

$$
S=\left(x_{S}-x_{W}\right)\left(y_{E}-y_{S}\right) .
$$

Then the nodal points' contributions in the interpolation will be proportional to the areas lying against the considered nodes:

$$
\delta_{W}=S_{E} / S, \quad \delta_{N}=S_{S} / S, \quad \delta_{E}=S_{W} / S, \quad \delta_{S}=S_{N} / S .
$$

Taking into account the concepts and notation introduced, the formula of linear interpolation on alternative areas will have the following form:

$$
U_{1}=U_{W} \delta_{W}+U_{N} \delta_{N}+U_{E} \delta_{E}+U_{S} \delta_{S}
$$

The values of the interaction constants $\sigma$ and $\varepsilon$, included in the Lennard-Jones potential, for some pairs of substances are given in the following table:

Table 1.

\begin{tabular}{|c|c|c|}
\hline Interacting molecules & $\begin{array}{c}\text { Relative depth of the } \\
\text { potential well }\end{array}$ & $\begin{array}{c}\text { Influence radius of the interaction } \\
\text { potential }\end{array}$ \\
\hline $\mathrm{C}-\mathrm{C}$ & $\varepsilon / k=51,2 \mathrm{~K}$ & $\sigma^{\prime}=0,335 \mathrm{~nm}$ \\
\hline $\mathrm{He}-\mathrm{He}$ & $\varepsilon / k=5,5 \mathrm{~K}$ & $\sigma^{\prime}=0,228 \mathrm{~nm}$ \\
\hline
\end{tabular}




$$
\begin{array}{c|c|c}
\mathrm{CH}_{4}-\mathrm{CH}_{4} & \varepsilon / k=146,7 \mathrm{~K} & \sigma^{\prime}=0,386 \mathrm{~nm}
\end{array}
$$

In Table $1 k$ is the Boltzmann constant.

If the system under study consists of heterogeneous molecules (atoms), for the parameters $\sigma$ and $\varepsilon$ the following averaging rules (the Lorentz-Berthelot mixing rules) are observed:

$$
\sigma_{12}=\frac{\sigma_{11}+\sigma_{22}}{2}, \varepsilon_{12}=\sqrt{\varepsilon_{11} \varepsilon_{22}}
$$

In this paper we consider a system of 11 nanoparticles of a $1 \mathrm{~nm}$ radius randomly filling the area of $110 \mathrm{~nm}^{2}$ as a porous element.

The origin of coordinates is put at the centre of the area under consideration, test molecules starting to move in the positive direction of the $0 y$ axis. The permeable edges of the rectangle are located along the $0 x$ axis. Thus, on stochastic filling of the considered volume with nanoparticles, we know the coordinates of the nanoparticles' centres included in the right-hand sides of scalar equations (4). These equations are integrated numerically. In addition, at each time step ( $\left.\Delta t=10^{-5} \mathrm{~ns}\right)$, and even at each point of conversion within this step, it is necessary to know the distance between the centre of the test molecule and the centre of an individual nanoparticle which is determined in the usual way:

$$
\rho_{j}=\sqrt{\left(x-x_{j}^{0}\right)^{2}+\left(y-y_{j}^{0}\right)^{2}}
$$

where $x, y$ are the coordinates of the moving molecule.

\section{Calculation results}

Naturally, in the compacted nanomaterial the line pore size has the order of the size of nanoparticles. If the value of this size to determine the Knudsen number, it turns out that in the pore space the molecule move in free-kinetic regime, i.e., without interaction. Therefore, triggers molecules whose trajectories are shown in Figure 2 were independent. Analyzing the path shown in the Figure 2, it is possible to conclude that Van der Waals forces have the strong influence on the nature of the molecules.

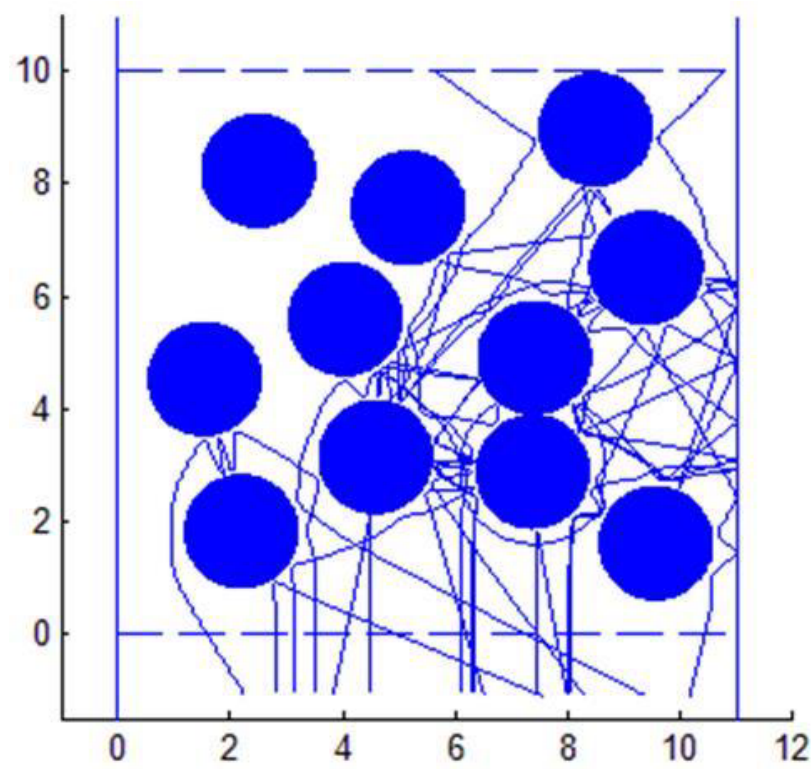

Figure 2. Trajectories of helium molecule motion. 
Statistical aspects of molecular ballistics are solved on the basis of [24-30].

Permeability $(D)$ is the ratio of the number of molecules passing through the layer to the number of floated molecules in the direction of the layer. The porosity $(\sigma)$ in the plane case is the ratio of the free area (not occupied by the particles) to the area of the whole fragment of the layer.

Permeability of a nanoparticle layer is insignificantly dependent on the particles' initial velocity. The results for helium molecules passing through a layer of carbon particles with the porosity of 0.8 are presented in Table 2 .

Table 2.

\begin{tabular}{|c|c|c|l|l|l|l|l|l|}
\hline$v_{0}(\mathrm{He})$ & 551 & 751 & 951 & 1151 & 1351 & 1551 & 1751 & 1951 \\
\hline$D(H e)$ & 0,192 & 0,141 & 0,126 & 0,185 & 0,372 & 0,258 & 0,261 & 0,114 \\
\hline
\end{tabular}

Permeability of the nanoparticle layer for the considered molecules depending on porosity is shown in Table 3.

Table 3.

\begin{tabular}{|l|l|l|l|l|l|l|}
\hline$\sigma($ material $)$ & 0,5145 & 0,6287 & 0,7144 & 0,7715 & 0,8286 & 0,9143 \\
\hline$D(\mathrm{He})$ & 0,0153 & 0,0571 & 0,1199 & 0,1334 & 0,2507 & 0,8295 \\
\hline$D\left(\mathrm{CH}_{4}\right)$ & 0,0147 & 0,0568 & 0,0735 & 0,0817 & 0,1316 & 0,4465 \\
\hline
\end{tabular}

Porosity is calculated by the following formula:

$$
\sigma^{*}=\frac{S_{n}-S_{p}}{S_{n}}
$$

where $S_{n}$ is the rectangle area and $S_{p}$ is the area of all the particles contained.

Thus, we can conclude that helium passes through a layer of carbon nanoparticles 2 times better than all other components. This result is confirmed by the experiments conducted by V.I. Romandin at the lab.35 of the Applied Mathematics and Mechanics Research Institute for various samples of ceramics.

\section{Acknowledgment}

This paper was written within the frame of Competitiveness Improvement Program of Tomsk State University.

\section{References}

1. C. R. Martin, Science, 266 (1994)

2. J.-R. Li, R. J. Kuppler, H.-C. Zhou, Chem. Soc. Rev., 38 (2009)

3. D. M. Dotzauer, J. Dai, L. Sun, M. L. Bruening, Nano Lett., 6 (2006)

4. T. Simons, U. Simon, Beilstein J. Nanotechnol., 3 (2012)

5. P. Kohli, C. C. Harrell, Z. Cao, R. Gasparac, W. Tan, C. R. Martin, Science, 305 (2004)

6. T. Suteewong, H. Sai, R. Hovden, D. Muller, M.S. Bradbury, S.M. Gruner, U. Wiesner, Science, 340 (2013)

7. M. A. Shannon, P. W. Bohn, M. Elimelech, J. G. Georgiadis, B. J. Mariñas, A. M. Mayes, Nature, 452 (2008)

8. P.V. Komarov, P.G. Khalatur, A.R. Khokhlov, Beilstein J. Nanotechnol., 4 (2013)

9. E.A. Jackson, M.A. Hillmyer, ACS NANO, 4 (2010) 
10. H.W. Kim, H.W. Yoon, S. Yoon, B.M. Yoo, B.K. Ahn, Y. H. Cho, H.J. Shin, H. Yang, U. Paik, S. Kwon, J. Choi, H.B. Park, Science, 342 (2013)

11. R. v. Reis, A. Zydney, Curr. Opin. Biotechnol., 12 (2001)

12. A. Kros, R. J. M. Nolte, N. A. J. M. Sommerdijk, Adv. Mater., 14 (2002)

13. E. Krieg, H. Weissman, E. Shirman, E. Shimoni, B. Rybtchinski, Nat. Nanotechnol., 6 (2011)

14. X. Peng, J. Jin, Y. Nakamura, T. Ohno, I. Ichinose, Nat. Nanotechnol., 4 (2009)

15. S.Y. Yang, I. Ryu, H. Y. Kim, J. K. Kim, S. K. Jang, T. P. Russell, Adv. Mater., 18 (2006)

16. P.M. Budd, N.B. McKeown, Polymer Chemistry, 1 (2009)

17. A. M. M. Jani, E. J. Anglin, S. J. P. McInnes, D. Losic, J. G. Shapter, N. H. Voelcker, Chem. Commun., 3062 (2009)

18. T.D. Lazzara, K. H. Aaron Lau, W. Knoll, A. Janshoff, C. Steinem, Beilstein J. Nanotechnol., 3 (2012)

19. A. K. Bohaty, I. Zharov, Langmuir, 22 (2006)

20. E. E. Nuxoll, M. A. Hillmyer, R. F. Wang, C. Leighton, R. A. Siegel, ACS Appl. Mater.

Interfaces, 1 (2009)

21. I. Vlassiouk, P. Y. Apel, S. N. Dmitriev, K. Healy, Z. S. Siwy, Proc. Natl. Acad. Sci. USA, 106 (2009)

22. A.M. Bubenchikov, M.A. Bubenchikov, A.I. Potekaev, E.E. Libin and Y.P. Khudobina, Izvestiya vuzov. Physics, 58, 7 (2015)

23. J. Ortega, New York. : Academic Press 1976, 340.

24. A.I. Potekaev, A.M. Bubenchikov, M.A. Bubenchikov, Russ. Phys. J., 55, 12 (2013)

25. M.A. Bubenchikov, A.I. Potekaev, A.M. Bubenchikov, Russ. Phys. J., 56, 3 (2013)

26. M.A. Bubenchikov, A.I. Potekaev, A.M. Bubenchikov, Russ. Phys. J., 56, 7 (2013)

27. A.M. Bubenchikov, M.A. Bubenchikov, A.I. Potekaev, A.S. Maslov, V.V. Ovcharenko, O.V.

Usenko, Russ. Phys. J., 57, 7 (2014)

28. M.A. Bubenchikov, A.M. Bubenchikov, O.V. Usenko, A.V. Ukolov, IOP CONF. SER. MATER. SCI. ENG, 87, 1 (2015)

29. M.A. Bubenchikov, A.I. Potekaev, A.M. Bubenchikov, Appl. Mech. and Mater., 698 (2015)

30. A.M. Bubenchikov, M.A. Bubenchikov, A.I. Potekaev, E.E. Libin and Y.P. Khudobina, Russ.

Phys. J., 57, 8 (2014) 